\title{
Research on Cultivation of Creative Class under Industrial Environment Cluster-- Take Cartoon Game Industry as an Example
}

\author{
Lie Chen
}

\author{
Sichuan University, Chengdu, 610000, China
}

Keywords: cartoon game industry; cluster; creative class; structure

\begin{abstract}
This research takes Chengdu national-level culture creative industry park as an example to pay attention to the current situation of cluster cultivation of creative class of Chengdu cartoon game industry under cluster environment. Through deep research on typical cartoon culture creativity enterprises, this paper carries out analysis on various factors influencing development of Chengdu professional cartoon creative talents, and proposes the solution for cultivation of creative talents based on the thought of cluster development of creative industry. The concept of industrial cluster firstly appeared in the book The Competitive Advantage of Nations written by Michael E. Porter and published in 1990. So far, as a kind of extremely special industrial organization form, the industrial cluster has gradually become an important economic phenomenon in world economic development. The powerful technology and knowledge overflow effect brought by industrial cluster is widely affecting industrialization and urbanization process of a region and even whole country. The cartoon industry which centers on Sichuan Chengdu is gradually forming Southwest cartoon industry development zone led by games and wireless entertainment. In the development process "from industrial concentration to grouping and cluster", the spatial arrangement of Chengdu cultural creative industry cluster has basically taken the shape, and the creative class cluster is basically formed. Currently, there are more than 520 software enterprises in Chengdu, including more than 60 online game enterprises. Take high-tech zone as an example: more than 180,000 various kinds of talents gather in Chengdu high-tech zone, including more than 15,000 overseas high-level talents, doctors, foreign experts, and other senior talents. Besides, in Chengdu City, there are 12 people selected into central government "thousand-talent plan" and 26 people selected into Sichuan "hundred-talent plan". Those high-level talents are mainly distributed in Chengdu High-tech Zone, Shuangliu County, Longquanyi District, and Jinniu District, etc.; the high-tech zone has most high-level talents, including 8 people selected into "thousand-talent plan" and 21 people selected into "hundred-talent plan". As the primate city of time development of western creative industry, Chengdu shall regard incubation of creative class as primary task to serve for the development of Chengdu cartoon game industry and provide talent guarantee for establishing "internationally advanced, domestic leading, west first" digital game cartoon content originality base.
\end{abstract}

\section{Investigation plan}

\section{Investigation purpose}

This investigation aims at summarizing the main factors which influence cultivation of Chengdu cartoon game creative lent aggregation and exploring new mode which adapts to cultivation of Chengdu creative class through investigation on current situation of creative talent aggregation in Chengdu creative park.

\section{Investigation object and method}

This investigation is a field investigation for typical cultural creative industry cluster area in Chengdu City; meanwhile, the corresponding cultural creative industry is taken as typical case for tracking research. Three representative game companies (UbiSoft, Perfect World, and GameWorks) are selected for key data sampling.

\section{Investigation content}

According to the growth environment and occupational states of cartoon game talents in typical creative park, the analysis is made on the reason why the structural contradiction happens between 
talent demand and talent supply so as to provide reference suggestions for cultivation of creative class.

\section{Investigation result and analysis}

1. Compared with rapid development of Chengdu cartoon game industry, the increment of creative talent aggregation is significantly insufficient with obvious individual difference in occupational ability.

In New York, the talents of cultural creative industry account for $12 \%$ of total working population; in London, this proportion is up to 14\%; in Tokyo, this proportion is up to $15 \%$; however, in Beijing, Shanghai and other metropolis in China, the proportion of employees of creative industry in total employed population is less than 1\% [2]. Most of those employees are only skill-oriented creative execution personnel, and the true sense of creative talents who take proprietary intellectual property rights as focus, take "brain" service as feature, and take professional or special skills as means are more rare, thus it is neither able to meet the demand of creative industry under continuous development nor able to reflect the group effect of creative talents[3]. There exists great gap between industrial demand and reserve of talents.

The investigation shows that the tapping degree of creative talents' ability is in highly positive correlation in the creative talents' social experience and education background. Due to individual difference, there also exists great difference in enterprises' cultivating creative talents. Under the cultivation of same post and same route, the game talents also show different growth features. In game cartoon industry, the high-level talents is extremely deficient, and the high mobility becomes the common occupational selection for the talents of this industry.

\section{Chengdu cartoon game creative group has unreasonable structure and low education level.}

The creative talents are a kind of intellectual laborers with creative thinking. On one hand, they have deep understanding of history and culture; on the other hand, they get hold of high-end professional skills, thus they are outstanding talents who take creative thinking service as feature and special skills as means. However, "the biggest gap between currently Chinese creative talents and international professional talents is lacking of combination ability of arts and technology, thus the urgent affair is to solve quality different." [4]

3. The creative talents have low recognition degree of realization of their own value, and low satisfaction of employment.

The investigation shows that there exist many problems in cartoon game talents' employment and individual development. For example, the initial employment is easy, but it is difficult to form a benign career growth; the enterprise salary system is imperfect; the enterprises have few paths to pay attention to talent growth; there is large mobility in middle and low-end creative talents. In addition, the uneven enterprise development level results in creative talents' low realization degree of their value and low satisfaction of employment.

\section{Analysis on necessity of cultivation of Chengdu creative class and factors restricting the cultivation of Chengdu creative class}

\section{(I) Analysis on necessity of cultivation of Chengdu cultural creative class}

John Hawkins pointed out in the book Creative Economy that half of working population in Group of Seven engaged in creative industry in 2004, and its increase speed was 2 times quicker than that of traditional service industry, and 4 times quicker than that of manufacturing industry, which meant that the creative class would become a tower of strength of social class of developed countries. As for the United States with rapid development of creative industry, it calls cultural creative industry as "copyright industry", and it is also the country with most developed copyright industry in the world.

According to investigation in 2006, the creative class and core creative personnel in Beijing accounted for $15.97 \%$ and $3.89 \%$ respectively; the creative class and core creative personnel in Shanghai accounted for $10.67 \%$ and $1.89 \%$ respectively; the creative class and core creative 
personnel in Chengdu accounted for $9.13 \%$ and $1.33 \%$ respectively. Currently, Shanghai has become one of cities with rapid development, the biggest total strength, and mature industrial form in China. In recent years, Beijing cultural creative industry has rapid development; by the end of 2012, the industrial added value of Beijing City has broken through RMB 200 billion yuan and been up to RMB 218.92 billion yuan, accounting for $12.3 \%$ of GDP. Shanghai culture industry keeps a trend of stable growth, and the gross output of cultural industry increases from RMB 168.699 billion yuan in 2005 to RMB 379.869 billion yuan in 2011; the added value of cultural industry increases from RMB 50.923 billion yuan in 2005 to RMB 109.897 billion yuan in 2011; the creative industry is becoming an eye-watching bright spot in Shanghai economic growth.

Although the total quantity of Chengdu creative talents can meet the demand of industrial development, the high-end creative talents are rare and the talent structure is imbalanced. Lacking of operation management personnel of creative industrialization has become an important factor which restricts the development of Chengdu cartoon game industry. However, by virtue of unique humanity, talent, and habitation advantage and as the industrial basis of important strategic and functional deployment area for development of national software industry, Chengdu has formed software, information technology service industry enterprise cluster, and complete industrial development system with certain scale and has been included in major strategic arrangement of national cartoon game industry revitalization, digital media technology application, and online game industry development. By the end of 2010, Chengdu has gathered about 210 enterprises which involve domestic and foreign digital game cartoon development, operation, and cultivation of professional talents, and the employment personnel is about 30,000, which forms a game cartoon and service supporting industry cluster led by media group, Kingsoft, Tencent, and SNDA, etc.; the online game research and development ability is ranked at top 3 in China.

\section{(II) Analysis on factors restricting the cultivation of Chengdu creative class}

1. There exist some problems such as old-fashioned cultivation mode, and single cultivation channel as for cultivation of local creative talents.

Although many universities in Chengdu have established the major related to creative industry and carried out cultivation of creative talents in order to adapt to the development of cultural creative industry in social market, it is unable to cultivate creative talents which meet enterprise demand due to traditional and old-fashioned cultivation mode, insufficient faculty, and single school and enterprise cooperative channel; as for most students, the occupation loss happens 1 year after their initial employment.

2. The enterprises pay attention to "employment" and lack of cultivation, and it is hard to form occupational commitment. Currently, what the enterprises most lack of is compound creative talents who both have deep cultural deposits and artistic accomplishment, and master economic management knowledge and marketing knowledge. The cultivation of such kind of talents often need 5-10 years, and even longer time.

3. Chengdu creative industry talent policy is imperfect. Chengdu points out in the research report of Chengdu Cultural Industry Talent Planning completed under the coordination of municipal academy of social sciences: in terms of total quantity of talents, the talents in Chengdu City can meet the demand of industrial demand, but the main problem is imbalanced talent structure. The scarcity of creative talents and industrial leading talents results in low professional degree of current industrial personnel and weak overall strength, which also becomes an important aspect which restricts development and further improvement of Chengdu cultural creative industry.

4. Compared to developed regions, the creative talent environment of Chengdu is still backward and has weak attraction to middle and high-end creative talents. Compared to creative talent attraction policy in Beijing, Shanghai, and Shenzhen, Chengdu has a weak working environment, development chance and treatment; the immature talent introduction policy of Chengdu results in a situation that the excellent creative talents gather in Beijing and Shanghai, but the creative talents in Chengdu have low professional degree and weak overall strength. 


\section{Countermeasures and suggestions for cultivation of creative class in Chengdu}

\section{(I) To reform education mode and perfect cultural creative talent cultivation system.}

Firstly, the creative thinking shall be cultivated. As for cultivation of creative thinking, it is required to improve creative awareness, and pay attention to creating of learning environment atmosphere. The schools shall fully exert students' subjective initiative according to students' personal features to enlighten students' creative thinking, stimulate students' potential, and guide students to actively explore problems. Meanwhile, it is required to greatly enhance culture and art quality education, increase the proportion of cultural creative courses, stimulate students' creative desire, and stimulate students to apply creative thinking to solve problems in study and daily life through combination of classroom teaching and extracurricular guidance. Secondly, it is required to quicken the construction of cultural creative teacher team. As for cultivation of cultural creative talents in colleges and universities, the high-level creative faculty is necessary. Except for deep knowledge of cultural creative theory, the attention shall be also paid to creative teachers' creative experience and practical experience. Thirdly, the construction of creative practice base shall be expanded. The cultural creative industry emphasizes marketization and commercialization of culture and art; however, under the requirements of knowledge inheritance and cultural innovation, it is required to determine the concept of paying attention to practice and construction internal and external cooperation (training) base of creative talents in the cultivation of cultural creative talents. [5]

(II) Chengdu municipal government shall pay attention to occupational status of creative talents, and perfect talent supporting policy.

It is required to establish perfect public service mechanism, and carry out industrial development and survey on talent demand on a regular basis; establish annual statistical system of cultural creative industry talent information and cultural creative industry talent database, master basic talent information, and implement dynamic management to provide consulting and service for talent development of culture enterprises. Besides, it is able to gather various kinds of creative talents through academic exchange, cooperative study, and technological development in a way of flexible introduction such as transfer, position recruitment, project recruitment, and talent leasing.

It is required to enhance introduction on high-end talents, pay attention to occupational development status of creative talents, encourage cooperation among social training organization, scientific research institutions, universities, and enterprises to establish multi-level and multi-channel talent cultivation system so as to provide talent guarantee for development of cultural creative industry. It is required to enhance the support for creative talent supporting fund, implement special subsidy expenditure for creative education development, and provide fund award for institutions which train large quantity of excellent creative talents; provide enterprise development with financing platform, and encourage creative talents to actively devote themselves to cultural creative industry through education training, intellectual property protection, and industrial management; perfect the relevant legislation of Chinese relevant intellectual property, enhance the management mechanism of intellectual property, and establish law enforcement agencies; carry out publicity work related to intellectual property, and enhance people's awareness of property right to ensure that the creative talents' rights and interests are not infringed.

(III) To establish reasonable and healthy creative talent growth channel.

The creative enterprises can take establishing independent creative talent training department as an important strategic investment, and customize long-term personal occupational growth plan for the creative talents of enterprises to make employees' growth fully integrated with enterprise growth and create a benign career growth route for creative talents so as to promote creative talents and market demand to form a virtuous circle.

It is required to pay attention to establishment of internal incentive system, and implement dual incentive of spiritual incentive and material incentive; encourage creative talents to fully exert their subjective initiative, and pay attention to self-value realization of creative talents. In terms of material level, it is able to adopt "share option" long-term incentive plan. The share option is a kind 
of long-term effective sharing mechanism with delayed payment period; it can connect enterprise senior talents with uncertainty of enterprise long-term earnings and provide a kind of preferential tax rate capital accumulation method while ensuring long-term reservation and attraction of senior talents so as to effectively creative talents' creative awareness and competitive awareness, and realize win-win of enterprises and employees.

A good enterprise culture creativity atmosphere is an important external environment for growth of creative talents. In terms of soft environment, it is required to make efforts to create loose, free, and open external environment, improve comfort level of office environment, expand public space region, and add necessary leisure places to mitigate work pressure and stimulate creative talents' potential.

\section{Acknowledgments}

This paper is a phased result of the project of Sichuan Philosophy and Social Science Key Research Base Cultural Industrial Development Research Center - research on cultivation of culture creativity group which adapts to the development of Chengdu culture creative industry cluster area, and the project number is CHY2013B01.

\section{References}

[1] Li Wuwei: Creativity Changes China [M], Beijing Xinhua Publishing House, 2009.

[2] Zhang Jingcheng: Development Report on Chinese Creative Industry (2006) [R], Beijing: China Economic Publishing House, 2006.

[3]John Howkins.The Creative Economy:How People Make Money from Ideas[M].London:Penguin Global, 2002.

[4] Yue Song, Li Yan, Wu Hongyu: Interpretation on Construction Status of Chinese Creative Industry Talent System [J], Research On Development, 2007 (5).

[5] Yin Baoliang: Discussion on Cultivation Mode of Cultural Creative Talents [J], Social Scientist, 2009 (10): 126-128. 